\title{
Profesyonel Futbolcuların Bilgisayar - İnternet Ve Playstation Oyunları Kullanımına İlişkin Görüşleri
}

\author{
DOI: 10.26466/opus.627504
}

\author{
* \\ Mikail Tel * \\ * Doç. Dr., Fırat Üniversitesi, Spor Bilimleri Fakültesi, Elazı $\breve{g}$ \\ E-Posta: mikailtel@gmail.com \\ ORCID: 0000-0002-0629-7357
}

$\ddot{O} z$

Bu çalışmanın amacı profesyonel futbolcuları, bilgisayar, internet ve playstation oyunlarına ilişkin görüşlerinin belirlenmesidir. Araştırmanın örneklemini Türkiye' de farklı kulüplerde profesyonel olarak futbol oynayan 154 futbolcudan oluşmaktadır. Bu araştırma tarama modelinde olup, betimsel bir nitelik arz etmektedir. Verilerin elde edilmesinde araştırmacilar tarafindan geliştirilen anket formu kullanılmıştır. Verilerin analizinde yüzde frekans, aritmetik ortalama ve standart sapma teknikleri kullanılmıştır. Demografik verilere dayalı karşılaştırmalarda tek yönlü varyans analizi kullanılmıştır. Demografik verilere bakıldığında yaşları genç, üniversite mezunu veya okuluna devam eden ve bekar bireylerden oluşmaktadır. Profesyonel futbolcuların \% 43,9'unun süper lig de ve \%52.0' nın da 3. liğ de oynadıklar belirlenmiştir. Araştırmaya katılanların \%84,3'ünün kendilerine ait bilgisayarlarının olduğu belirlenmiştir. Internet kullanma süreleri \%50 1-2 saat kullandıkları belirlenmiştir. Araştırmaya katılanların $\% 56,2$ 'si her zaman playstation oynadıkları belirlenmiştir. Araştırmaya katılanların \% 76,1'i 1 saat, \%14.1 2 saat playstation oynamaktadır. Playsation oyunların evde oynadıkları belirlenmiştir. Oynadikları oyunlara bakıldığında futbol ve okey- satranç- tavla oynadıkları belirlenmiştir. Araştırmaya katılanların eğlenmek ve stres atmak amacıyla oynadıkları belirlenmiştir. Araştırmaya katılanların PES ve FİFA adlı oyunu oynadıkları belirlenmiştir. Profesyonel futbolcuların \%83.8' nin e postası olduğu, \%70.8 nin msn, \%82.5 nin de facebook kullandığı belirlenmiştir. Sonuç olarak, profesyonel futbol oynayan futbolcular bilgisayar-interneti sıklıkla kullandıkları, iletişime açık oldukları, playstation oyunların sıklikla ve futbol oyununu oynadıkları belirlenmiş̧tir. Profesyonel futbolcuların playstation oyunlarını gerçek bir oyunmuş gibi algıladıkları ve oynadıkları belirlenmiştir.

Anahtar Kelimeler: Futbol, Profesyonel Futbol, Playsation ve Futbol, 


\title{
Perceptions Of Professional Football Players About Using Computer - Internet And Playstation Games
}

\begin{abstract}
The aim of this study is to determine the perceptions of professional players about computers, the internet and PlayStation games. The sample of the study included 154 football players who professionally play football in various clubs in Turkey. This study was conducted with a survey model and had a descriptive quality. In the data collection, the survey form created by the researchers was used. In the data analysis, frequency, arithmetic means and standard deviation techniques were used. In the comparisons based on demographic data, one-way variance analysis was used. Considering the demographic data, the participants consisted of young individuals who were either studying in university or graduated and were single individuals. It was also determined that $43.9 \%$ of the professional football players played in the super league and $52.0 \%$ of them played in the $3^{\text {rd }}$ league. It was determined that $84.3 \%$ of the participants in the study owned personal computers. As for the time of using the internet, it was determined that $50 \%$ of them used it for 1-2 hours. It was determined that $56.2 \%$ of the participants always played PlayStation.76.1\% of the participants played PlayStation games for 1 hour while $14.1 \%$ of them played for 2 hours. It was determined that they played PlayStation games at home. Considering the games played by the participants, it was determined that they played football and tiles-chess-backgammon. It was determined that the participants in the study played games for having fun and relieving stress. It was determined that the participants in the study played games called PES and FIFA. The professional football players stated that $83.8 \%$ of them had e-mail addresses while $70.8 \%$ of them used MSN and $82.5 \%$ of them used Facebook. In conclusion, it was determined that the professional football players used computers-internet frequently and they were open for communication. Additionally, it was determined that they played PlayStation games frequently and played football games. It was finally concluded that the professional football players perceived and played PlayStation games as real games.
\end{abstract}

Keywords: Football, Professional Football, PlayStation and Football 


\section{Giriş}

Günümüz bilim ve teknoloji dünyasındaki hızlı gelişmeler toplumsal hayatın her alanını etkilemektedir (Yaman ve Yaman, 2008). Bilgisayar ve internet günlük hayatımızın içerisinde önemli bir yer tutmakta ve hayatımızın her alanında kullanılmaktadır (Önür ve Kalaman, 2016). İnternet insanların bilgi saklamak, paylaşmanın yanı sıra bilgiye kolay ulaşma gereksiniminden ortaya çıkmış, birden çok bilgisayar sistemlerinin "TC/IP" protokolü ile birbirilerine bağlı olduğu ve dünyada giderek daha çok gelişen evrensel bir iletişim ağ olarak ifade edilir (Wingate, 2001). Başka bir kavramla internet, dünya üstündeki farklı bilgisayar ağlarının ortak bir dil ağında bilgisayarların birbirilerine bağlamak suretiyle, bireylerin bilgileri paylaşma olanağı sağlayan evrensel bir ağ olarak ifade edilmektedir (Köksal ve Ark., 1999).

Dünyada 1993 yılındaki interneti kullanan birey sayısı, "900 bin" civarında iken, 2002 yılı Şubat ayında "544,2 milyon" internet kullanıcısı, 2004 yılının sonlarında ise "934 milyon" internet kullanıcı sayısına ulaşılmıştır. (İnternet, www.glreach.com/globstats/). Dünyada interneti kullanan kişi sayısı 2005 yllının sonunda ise 1,07 milyara, 2007 yllının sonunda ise 1,35 milyar kişiye ulaşmıştır. (www.ntvmsnbc.com/news/288144.asp). Türkiye İstatistik Kurumu 2018 yılında hane halkı Bilişim Teknolojileri Birimi araştırma neticesinde 74 yaşındaki bireylerde internet kullanım seviyesi $\% 72,9$ oranına yükselmiştir. Bilgisayar ve İnternet kullanımı 2018 yılı verilerine göre

16-74 yaş aralığında yer alan grupda sırasıyla; \%59,6 iken \%72,9 sevilerinde olduğu belirlenmiştir. 2017' de bu oranlar sırasıyla; \%56,6 seviyesinde iken $\% 66,8$ seviyesine yükselmiştir. Bilgisayarı ve İnterneti kullanma seviyesi "16-74 yaş aralığındaki erkek bireylerde" \%68,6 oranından \%80,4 oranına, kadın kullanıcılarda ise \%50,6 oranından \%65,5 oranına yükselmiştir. Bu sonuçlar dışında her 10 haneden 8 'inde internetin olduğu belirlenmiştir. Bilişim teknolojileri hane halkı internet kullanımı araştırmaları neticesinde Nisan 2018 'de $\% 83,8^{\prime}$ i gibi bir oranda hanelerin evinde internet erişimine sahip olduğu belirlenmiştir (Tuik, 2018).

Günümüzde internet kullanan birey sayısı gün geçtikçe artmaktadır. Günlük hayatımızda dijital bağlantılar yaşamımızın bir parçası olmuştur. Yapılan araştırma sonuçlarına göre dünya nüfusunun büyük bir çoğunluğu en az bir tane akıllı telefon kullandığı ve dünya üzerindeki internet kullanımının büyük kısmının akıllı cep telefonlarından olduğu belirlenmiştir. Türkiye'de 
ise her geçen gün internet kullanımı ve kullanıcı sayısı sürekli artmaktadır. Türkiye'de "48 milyon" kişinin internete bağlandığı görülmektedir. (www.dijitalajanslar.com,2017). İnsanların internet kullanım oranlarının masa üstü ve taşınabilir bilgisayarlara göre akıllı telefonlarda daha fazla olduğunu ifade edilmiştir (Kaya ve Ark., 2017).

Teknoloji insanların mücadelesi olarak ortaya çıkmış bir ürün olup, bireylerin ilişkilerinde etkili olmasının yanı sıra farklı sosyal çevrelerin oluşmasında büyük katkı sağlamıştır (Bila, 2001). Toplumların yapısında olumlu veya olumsuz etkilerinin gözlemlendiği internet, insanların sosyal hayatlarının ve kültürlerinin üzerinde değişiklikler oluşturması kaçınılmaz bir neticedir. Ayrıca internet pek çok teknolojik bileşeni (ses, grafik ve video, vb.) birlikte sunan teknoloji oluşunun yanında, kişilerin bu yollar ile haber aldığı ve aldığ 1 bu haberlerle eğlendiği, eğitildiği, bunun yanında bu haberlere karşın anında memnuniyet ve tepki gösterebilmesi, internetin kullanımının insanlar arasında tercih edilmesi ve yaygınlaşmasında önemli bir etkendir (Akbaş, 2002).Internet bireyler arasında pek çok kültürel ve fiziksel özellikleri ( mesafe, yaş, cinsiyet, ırk, kültür, vb.) ortadan kaldırmaktadır.

İnternetin oluşturduğu anonim karakterler ve benzer biçimde düşünen kişilerin, zamanın ve mekânın durumuna bağlı kalmaksızın kolayca bir araya gelip, sanal topluluk oluşturmak, farklı kültürden kişilerin birbirini tanıma imkanı sunmak, sanal olarak başlanan ilişkilerden reel yaşama geçen ilişkilerin oluşmasının yanı sıra bireylerin tüm düşüncelerini özgürce ifade edebilmesi sosyal yaşamda görülen en büyük değişimlerdir (Bila, 2001).

Günümüzde internet yaşamın her alanında ve binlerce sektör tarafından kullanılan zaruri bir araçtır. İnternet ile yerinden alışveriş, bankacılık hizmetleri, işe gitmeyerek evde çalışma gibi kolaylıklar bireyin sosyal yaşamını da etkilemektedir (Bostanc, 2000). Bir çok alanda kullanılan bilgisayar-internet bunların dışında bir eğlence aracı olarak kullanıldığı bilinmektedir (Çelen ve ark., 2011, Kiran, 2013, Korkusuz ve Karamete, 2013). Çocuklar ile gençler internet ve bilgisayar ortamında sürekli oynadıkları oyunların olduğu bilinmektedir. Bu oyunlar genel olarak "Level Bilgisayar Oyunu Dergisinde"; "aksiyon, macera, motor sporları ve yarış, rol yapma, canlandırma, simülasyon, strateji ve spor oyunları" biçiminde sınıflandırılmıştır (Gürcan ve Ark., 2008, Binark ve Sütçü, 2011). 
Bilgisayarda oynanan oyunlar yalnızca çocukların değil gençler ile yetişkinlerinde eğlenceli zaman ve boş zamanlarını değerlendirmede sürekli yaptıkları bir etkinlik olduğu görülmektedir (Güllü ve Ark., 2012). Yapılan araştırmalar kız öğrencilerin erkek öğrencilerden daha fazla bilgisayar oyunu oynadıklarını belirlemiştirler (Tüfekçi,2007).

Spor oyunları içerisinde popüler olarak Playstation önemli bir yer tutmaktadır. Tüzün ve Özdinç yaptıkları çalışmada spor temasını barından oyunların en popüler oyunlar olduğunu ifade etmişlerdir (Tüzün ve Özdinç,2010). Araştırma grubundaki katılımcların en fazla oynadıkları üç oyunun futbol içeriği barındıran oyunlar olması ilgi çekicidir. Arnas yaptığı çalışmada çocukların oyun tercihlerinde $\% 23,3$ 'ü spor içerikli oyunlar oynadıkların belirlemiştir (Arnas, 2005). Tel yaptığı çalışmada ortaokul öğrencilerinin en çok tercih ettikleri oyunların FíFA olduğunu belirlemiştir (Tel, 2015).

Futbol insanlar arasında sürekli oynanan ve izlenen ve ayn zamanda dünya genelinde en fazla oynanmakta ve izlenmektedir. Türkiye'de lisanslı oyuncu sayısı olarak en fazla futbol branşında olduğu görülmektedir. Türkiye'de aktif olarak futbol branşında lisanslı oyuncu sayısı 602.465 kişidir (shgm.gsb.gov.tr). Ayrıca 2007 TÜIK verilerine göre amatör olarak aktif ve faal olarak lisanslı futbolcu sayısı 210.445 kişi olduğu görülmektedir (TÜİK, 2007). Bu araştırmanın amac1, toplumda sıklıkla takip edilen profesyonel olarak futbol hayatlarını devam ettiren kişilerin bilgisayar, internet ve playstation oyunları hakkındaki görüşlerini belirlemektir.

\section{Materyal ve Yöntem}

\section{Araştırmanın Amacı ve Yöntemi}

$\mathrm{Bu}$ araştırma profesyonel futbolcuların, bilgisayar, internet ve playstation oyunların kullanımına ilişkin görüşlerini belirlemek amacı ile yapılmıştır. Araştırma tarama modelinde olup, betimsel bir nitelik arz etmektedir. Tarama modelleri geçmişte ya da halen var olan bir durumu var olduğu şekliyle betimlemeyi amaçlayan araştırma yaklaşımlarıdır (Karasar, 2010). 


\section{Araştırmanin Evren ve Örneklemi}

Araştırmanın evrenini, Türkiye'deki 2015-2016 sezonu içerisinde mücadele eden takımlardır. Örneklemi ise bu kulüpler içerisinde seçilen ve ankete gönüllü olarak katılmak isteyen spor kulüplerindeki 154 profesyonel futbolcudan oluşmaktadır. Bu spor kulüpleri ‘Elazığspor, Diyarbakırspor, Adıyamanspor, Malatyaspor, Denizlispor' da oynayan profesyonel futbolculardan oluşmaktadır. Spor kulüplerinin ve oyuncuların tespitinde tesadüfi yöntem kullanılarak anketler gönüllük esasında uygulanmıştır.

\section{Veri Toplama Araci ve Uygulama}

$\mathrm{Bu}$ araştırmada, verileri anket yöntemi kullanılarak elde edilmiştir. Anket formu oluşturulurken yerli ve yabancı literatür taramasının yanı sıra alanında uzman kişilerin görüşleri de alınarak oluşturuldu. Ankette beşli likert dereceleme ölçeği kullanılmıştır. Dereceleme "Tamamen Katılıyorum, Katıllyorum, Kararsızım, Kısmen Katılıyorum, Hiç Katılmıyorum" şeklindedir.

Araştırmaya katılan profesyonel futbolcuların bilgisayar, internet ve playstation oyunlarına katılma durumlarına yönelik yapılan boyutun faktör analizi sonucunda; KMO; 0,684 ve Bartlett Testi; 550,184 ayrica Cronbach Alpha değeri 0,758 olarak bulunmuştur.

\section{Verilerin Analizi}

Verilerin analizinde SPSS istatistik paket program kullanılmıştır. Araştırmaya katılan sporcuların demografik bilgileri ve bilgisayar ve internet kullanım düzeylerini belirlemek için verilerin analizinde yüzde (\%)ve frekans(f) analizleri yapıldı. Araştırmaya katılan sporcuların yaş değişkenine göre; bilgisayar-internet kullanma ve bilgisayar-playstation oyunlarına katılma durumlarına ilişkin görüşlerini belirlemek için tek yönlü varyans analizi (ANOVA) kullanılmıştır.

\section{Bulgular ve Tartışma}

Bu bölümde, araştırma sonuçlarına ilişkin elde edilen bulgular tablolar halinde sunulmuş ve değerlendirilmiştir. 
Araştırmaya Katılan Profesyonel Futbolcularn Demografik Özellikleri ve Internet Kullanma Süreleri

Tablo 1. Araştırmaya katılanların yaş durumlarına göre dağılımı

\begin{tabular}{lll}
\hline Yaş & $\mathbf{f}$ & $\mathbf{\%}$ \\
\hline 20 yaş ve altı & 31 & 20,1 \\
$21-25$ yaş & 86 & 55,8 \\
26-30 yaş & 21 & 13,6 \\
31-35 yaş & 16 & 10,4 \\
35 yaş ve üstü & 0 & 0 \\
Toplam & $\mathbf{1 5 4}$ & $\mathbf{1 0 0}$ \\
\hline
\end{tabular}

Tablo 1'e bakıldığında araştırma grubunda yer alan sporcuların \% $20,1^{\prime}$ inin 20 yaş ve altında, $\% 55,8^{\prime}$ inin ise $21-25$ yaş aralığında olduğu belirlenmiştir. Araştırmada \% 13,6'sının 26-30 yaş aralığında, \% 10,4'ünün de 3135 yaşları arasında olduğu belirlenmiştir. Bu sonuçlar doğrultusunda profesyonel olarak futbol oynayan kişilerin \% 89,5'lik kısmının 30 yaş altında olduğu görülmektedir. Türkiye'de nüfusun büyük bir kısmının genç nüfus olması büyük potansiyel olarak görülmektedir (Ramazanoğlu, 2013).

Tablo 2. Araştırmaya katılanların medeni durumlarnna göre dağılımı

\begin{tabular}{lll}
\hline Medeni Durum & f & \% \\
\hline Evli & 45 & 29,2 \\
Bekar & 109 & 70,8 \\
Toplam & $\mathbf{1 5 4}$ & $\mathbf{1 0 0}$ \\
\hline
\end{tabular}

Tablo 2 değerlendirildiğinde sporcuların $\% 29,2$ 'sinin evli, \% 70,8'inin bekar olduğu belirlenmiştir.

Tablo 3. Araştırmaya katılanlarn eğitim durumlarına göre dağılımı

\begin{tabular}{lll}
\hline Eğitim Durumu & $\mathbf{f}$ & $\mathbf{\%}$ \\
\hline İkokul & 0 & 0 \\
Ortaokul & 3 & 1,9 \\
Lise & 88 & 57,1 \\
Üniversite & 63 & 40,9 \\
Toplam & $\mathbf{1 5 4}$ & $\mathbf{1 0 0}$ \\
\hline
\end{tabular}

Tablo 3'e bakıldığında katılımciların \% 1,9'unun ortaokul mezunu, \%57,1'inin lise düzeyinde öğrenim gördüğü ya da öğrenimlerine devam ettikleri, \% 40,9'unun da üniversite mezunu olduğu ve eğitimine devam ettiği 
görülmüştür. Bu sonuçlar katılımcların eğitim durumlarının lise ve üniversite düzeyinde oldukları söylenebilir.

Tablo 4. Araştırmaya katılanların bilgisayar durumlarına göre dağılımı

\begin{tabular}{lll}
\hline Bilgisayarinız Var mı? & f & \% \\
\hline Evet & 129 & 84,3 \\
Hayır & 24 & 15,7 \\
Toplam & $\mathbf{1 5 3}$ & $\mathbf{1 0 0}$ \\
\hline
\end{tabular}

Tablo 4 değerlendirildiğinde sporcuların \% 84,3'lük kısmının kendine ait bir bilgisayarının olduğunu, \% 15,7'lik kısmının ise kendine ait bir bilgisayarının olmadığ belirlenmiştir.

Tablo 5. Araştırmaya katılanlarn internet kullanım sürelerine göre dağılımı

\begin{tabular}{lll}
\hline İnternet Kullanum Süresi & f & $\mathbf{\%}$ \\
\hline 1 saatten az & 47 & 31,1 \\
2 saat & 43 & 28,5 \\
3 saat & 27 & 17,9 \\
4 saat & 13 & 8,6 \\
5 saat ve üzeri & 21 & 13,6 \\
Hiç kullanmiyorum & 0 & 0 \\
Toplam & $\mathbf{1 5 1}$ & $\mathbf{1 0 0}$ \\
\hline
\end{tabular}

Tablo 5'e bakıldığında katılımcıların internet kullanım süreleri sırasıyla, \% 31,1'inin günde bir saatten az, \% 28,5'inin günde iki saat, \% 17,9'unun günde üç saat, \%8,6'sının günde dört saat, \% 13,6'sının günde beş saat ve üzerinde internet kullandığı belirlenmiştir.

Tablo 6. Araştırmaya katılanların oynadıkları lige göre dağılımı

\begin{tabular}{lll}
\hline Eğitim Durumu & $\mathbf{f}$ & $\mathbf{\%}$ \\
\hline Süper lig & 65 & 43,9 \\
Bank Asya & 2 & 1,4 \\
2. Lig & 4 & 2,7 \\
3. Lig & 77 & 52,0 \\
Toplam & $\mathbf{1 4 8}$ & $\mathbf{1 0 0}$ \\
\hline
\end{tabular}

Tablo 6 incelendiğinde araştırmaya katılanların oynadıkları lig durumuna bakıldığında \% 43,9'unun süper lig, \% 1,4'ünün Bank Asya, \% 2,7'sinin 2. Lig ve $\% 52,0$ 'sinin 3 ligde futbol oynadıkları görülmektedir. 
Araştırmaya Katılan Profesyonel Futbolcularn Bilgisayar ve Playstation Oyunlarına Katılma Durumlarna İlişkin Görüşleri

Tablo 7. Araştırmaya Katılan Profesyonel Futbolcularn Playstation Oyunlar Oynama Durumlarna İlişkin Görüşler

\begin{tabular}{lll}
\hline Playstation oyunları oynuyor musunuz? & f & \% \\
\hline Evet & 81 & 56,2 \\
Bazen & 49 & 34,0 \\
Hayır & 14 & 9,8 \\
Toplam & $\mathbf{1 6 9}$ & $\mathbf{1 0 0 , 0}$ \\
\hline
\end{tabular}

Tablo 7'ye bakıldığında araştırma grubunun \% 56,2'sini playstation oyunu oynadıklarını, \% 34,0'ünün bazen oynadıklarını, \% 9,8'lik kısmının playstation oyunu oynamadıkları belirlenmiştir.

Tablo 8. Araştırmaya Katılan Profesyonel Futbolcuların Bilgisayar Oyunlarına Ayırdıklarn Sürelere İlişkin Görüşler

\begin{tabular}{lll}
\hline Bilgisayar oyunlarına günde ne kadar zaman ayıriyorsunuz? & f & $\mathbf{\%}$ \\
\hline 1 saatten az & 108 & 76,1 \\
2 saat & 20 & 14,1 \\
3 saat & 9 & 6,3 \\
4 saat & 2 & 1,4 \\
5 saat ve üzeri & 3 & 2,1 \\
Toplam & $\mathbf{1 5 3}$ & $\mathbf{1 0 0 , 0}$ \\
\hline
\end{tabular}

Tablo 8'e bakıldığında katılımcıların \% 76,1'inin 1 saatten daha az, \% 14,1'inin 2 saat, \%6,3'ünün 3 saat, \% 1,4'ünün 4 saat, \% 2,1'inin de 5 saat ve üzerinde zamanlarını bilgisayar oyunlarına ayırdıklarını belirtmişlerdir.

Tablo 9. Araştırmaya Katılan Profesyonel Futbolcularn Bilgisayar-Playstation Oyunlarını Nerede Oynadıklarına İlişkin Görüşler

\begin{tabular}{lll}
\hline Nerede oynuyorsunuz? & $\mathbf{f}$ & $\mathbf{\%}$ \\
\hline Evde & 67 & 47,9 \\
Oyun Salonlarında & 9 & 6,4 \\
Kulüp Tesislerinde & 58 & 41,4 \\
Diğer & 6 & 4,3 \\
Toplam & $\mathbf{1 5 5}$ & $\mathbf{1 0 0 , 0}$ \\
\hline
\end{tabular}


Tablo 9 incelendiğinde araştırma grubunun bilgisayar ile playstation oyunların, $\% 47,9^{\prime}$ u evinde, $\%$ 6, $4^{\prime}$ ü oyun salonunda, $\%$ 41,4'ü kulüp tesislerinde ve \% 4,3'ü ise ev, oyun salonu ve kulüp tesisleri dışındaki mekânlarda oynadıkları belirlenmiştir.

Tablo 10. Araştırmaya Katılan Profesyonel Futbolcularn Bilgisayar-Playstation Oyunlarnnda Hangi Tür Oyun Oynadıklarna İlişkin Görüşler

\begin{tabular}{lll}
\hline Bilgisayar-playstationda hangi tür oyunları oynuyorsunuz? & f & $\mathbf{\%}$ \\
\hline Futbol & 133 & 52,8 \\
Strateji-rol oynama & 29 & 11,6 \\
Araba yarışı & 20 & 8 \\
Savaş & 16 & 6,5 \\
Korku & 2 & 0,9 \\
Simülasyon & 3 & 1,4 \\
Flash oyunları (küçük oyunlar) & 6 & 2,4 \\
Tavla-Okey-Satranç & 43 & 17,1 \\
Toplam & $\mathbf{2 5 2}$ & $\mathbf{1 0 0 , 0}$ \\
\hline
\end{tabular}

Tablo 10'a bakıldığında, katılımcıların \% 52,8'si futbol, \% 11,6'sı strateji ve rol oynamak, \% 8,0'i araba yarışı, \% 6,5'i savaş oyunları, \% 0,9'u korku oyunları, \% 1,4'ü simülasyon oyunları, \% 2,4'ü flash oyunları (küçük oyunlar) ve $\%$ 17,1'i ise tavla, okey, satranç vb. oyunlar oynadıkları belirlenmiştir.

Tablo 11. Araştırmaya Katılan Profesyonel Futbolcularn Playstation Oyunlarmn Oynama Sebeplerine İlişkin Görüşleri

\begin{tabular}{lll}
\hline Niçin playstation oyunların oynuyorsunuz? & f & $\mathbf{\%}$ \\
\hline Eğlenmek & 96 & 40,9 \\
Stres atmak & 77 & 32,7 \\
Zeka geliştirmek & 24 & 10,2 \\
Boşzamanları değerlendirmek & 38 & 16,2 \\
Toplam & $\mathbf{2 3 5}$ & $\mathbf{1 0 0 , 0}$ \\
\hline
\end{tabular}

Tablo 11 incelendiğinde, futbolcuların \% 40,9'unun eğlenmek, \% 32,7'sinin stres atmak, \% 10,2'sinin zeka geliştirmek, \% 16,2'sinin boş zamanları değerlendirmek amaçlarıyla playstation oyunları oynadıkları görülmüştür. 
Profesyonel Futbolcuların Bilgisayar - İnternet Ve Playstation Oyunları Kullanımına İlişkin Görüşleri

Tablo 12. Araştırmaya Katılan Profesyonel Futbolcularn Oynadıkları Futbol Oyunlan Türüne İlişkin Görüşleri

\begin{tabular}{lcl}
\hline Hangi Futbol oyunlarını oynuyorsunuz? & f & \% \\
\hline FiFA & 75 & 34,1 \\
PES & 109 & 49,5 \\
Football Manager & 27 & 12,3 \\
Diğer & 9 & 4,1 \\
Toplam & $\mathbf{2 2 0}$ & $\mathbf{1 0 0 , 0}$ \\
\hline
\end{tabular}

Tablo 12 değerlendirildiğinde araştırma grubunun \% 34,1'i FIFA oynadığını, \% 57,0'si PES oynadığını, \% 13,0'i Football Manager oynadığını, \% 2,0'si ise diğer futbol oyunları oynadıkları belirlenmiştir.

Profesyonel Futbolcularn İletişime Sahip Olma Durumu ve Kullanma Stkliğına İlişkin Görüş̧leri

Tablo 13. Profesyonel Futbolcularn İletişime Sahip Olma Durumuna İlişkin Görüşleri

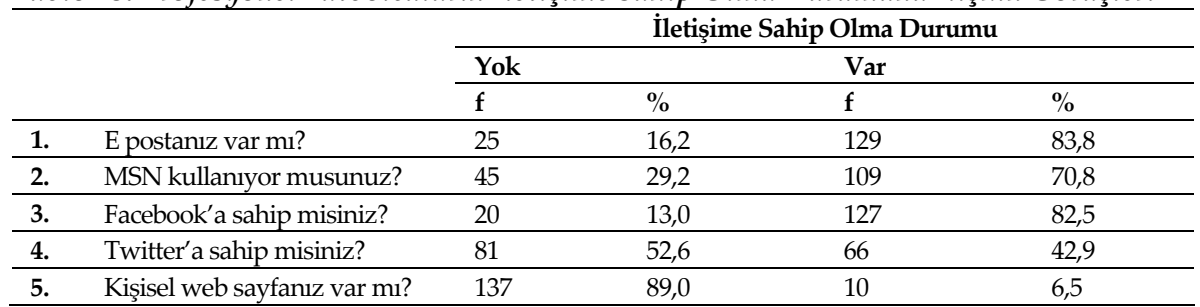

Tablo 13 incelendiğinde futbolcuların \% 83,8'si bir e-posta hesabına sahip olduğunu, \%70,8'i MSN kullandığını, \% 82,5'i Facebook hesabına sahip olduğunu, \% 42,9'u Twitter hesabına sahip olduğuna ve \% 6,5'i ise kişisel web sayfası olduğu belirlenmiştir. Bu sonuçlar katılımcıların sosyal medyada iletişim kurmaya önem verdiklerini göstermektedir.

Tablo 14. Profesyonel Futbolcuların İletişimi Kullanma Sıklığına İlişkin Görüşleri

\begin{tabular}{|c|c|c|c|c|c|c|c|c|c|c|c|}
\hline & & \multicolumn{10}{|c|}{ İletişime Sahip Olma Durumu } \\
\hline & & \multicolumn{2}{|c|}{ GBK } & \multicolumn{2}{|c|}{ HG } & \multicolumn{2}{|c|}{ HBK } & \multicolumn{2}{|l|}{ HB } & \multicolumn{2}{|c|}{ ABK } \\
\hline & & $\mathrm{f}$ & $\%$ & $\mathrm{f}$ & $\%$ & $\mathrm{f}$ & $\%$ & $\mathrm{f}$ & $\%$ & $\mathrm{f}$ & $\%$ \\
\hline 1. & E postaniz var mi? & 17 & 11,0 & 26 & 16,9 & 25 & 16,2 & 27 & 17,5 & 27 & 17,5 \\
\hline 2. & MSN kullaniyor musunuz? & 28 & 18,2 & 24 & 15,6 & 26 & 16,9 & 17 & 11,0 & 6 & 3,9 \\
\hline 3. & Facebook'a sahip misiniz? & 7 & 4,5 & 3 & 1,9 & 22 & 14,3 & 57 & 37,0 & 36 & 23,4 \\
\hline 4. & Twitter'a sahip misiniz? & 8 & 5,2 & 13 & 8,4 & 26 & 16,9 & 22 & 14,3 & 69 & 44,8 \\
\hline 5. & Kişisel web sayfanız var mı? & 81 & 52,6 & 49 & 31,8 & 14 & 9,1 & 0 & 0 & 0 & 0 \\
\hline
\end{tabular}

GBK (Günde birkaç kez), HG (Her gün), HBK (Haftada birkaç kez), HB (Haftadabir), ABK (Ayda birkaç kez 
Tablo 14 incelendiğinde futbolcuların \% 23,4'ü Facebook hesabını günde birkaç defa, \% 3,9'u MSN hesabını ayda birkaç defa kullandığı belirlenmiştir. Bu durum futbolcuların sosyal medyaya önem verdiğini söyleyebiliriz.

Araştırmaya Katılan Profesyonel Futbolcularn Bilgisayar ve İnternet Kullanımına İlişkin Görüşleri

\section{Araştırmaya Katılan Profesyonel Futbolcularn Yaş Değişkenine Göre Bilgisayar ve İnternet Kullanımına İlişkin Görüşleri}

Tablo 15. Araştırmaya Katılan Profesyonel Futbolcularnn Yaş Değişkenine Göre Bilgisayar ve İnternet Kullanımına İlişkin Görüşleri

\begin{tabular}{|c|c|c|c|c|c|c|c|c|c|}
\hline \multirow{2}{*}{$\begin{array}{l}\text { M. } \\
\text { No }\end{array}$} & \multicolumn{2}{|c|}{$\begin{array}{l}\text { 1-20 yaş }(a) \\
(n=67)\end{array}$} & \multicolumn{2}{|c|}{$\begin{array}{l}\text { 21-30 yaş (b) } \\
(n=77)\end{array}$} & \multicolumn{2}{|c|}{$\begin{array}{l}31 \text { yaş ve üzeri } \\
\text { (c) }(n=18)\end{array}$} & \multicolumn{2}{|c|}{ Varyans } & \multirow{2}{*}{$\begin{array}{l}\text { Fark } \\
\text { Olan } \\
\text { Gruplar }\end{array}$} \\
\hline & $\bar{X}$ & $S$ & $\bar{X}$ & $S$ & $\bar{X}$ & $S$ & $\mathbf{F}$ & $\mathrm{p}$ & \\
\hline 1 & 3,80 & 0,79 & 4,07 & 0,90 & 3,32 & 0,97 & $8,810^{*}$ & $0,000^{*}$ & $a-b, b-c$ \\
\hline 2 & 4,00 & 0,63 & 3,65 & 0,92 & 4,00 & 0,94 & 2,940 & 0,056 & \\
\hline 3 & 2,77 & 1,58 & 3,30 & 1,32 & 3,25 & 1,33 & 1,708 & 0,185 & \\
\hline 4 & 3,64 & 0,66 & 3,56 & 1,18 & 3,56 & 1,16 & 0,064 & 0,938 & \\
\hline 5 & 3,90 & 0,66 & 3,41 & 1,23 & 3,02 & 1,36 & $4,539 *$ & $0,012^{*}$ & $a-b, a-c$ \\
\hline 6 & 3,48 & 1,28 & 3,84 & 1,02 & 3,19 & 1,48 & $4,019^{*}$ & $0,020^{*}$ & $a-b, b-c$ \\
\hline 7 & 2,93 & 1,43 & 3,59 & 0,97 & 2,37 & 1,40 & $13,890^{*}$ & $0,000^{*}$ & $a-b, b-c$ \\
\hline 8 & 3,03 & 1,40 & 2,88 & 1,21 & 2,38 & 0,90 & 2,921 & 0,057 & \\
\hline 9 & 2,76 & 1,59 & 2,46 & 1,29 & 2,32 & 1,22 & 0,924 & 0,399 & \\
\hline 10 & 2,90 & 1,55 & 2,18 & 1,34 & 1,67 & 1,08 & $7,197^{*}$ & $0,001^{*}$ & $a-b, a-c$ \\
\hline 11 & 3,90 & 0,70 & 3,91 & 0,93 & 3,27 & 1,30 & $5,689^{*}$ & $0,004^{*}$ & $\mathrm{a}-\mathrm{c}, \mathrm{b}-\mathrm{c}$ \\
\hline 12 & 3,51 & 1,58 & 3,34 & 1,04 & 3,21 & 0,94 & 0,569 & 0,568 & \\
\hline 13 & 3,06 & 1,31 & 3,04 & 1,18 & 3,59 & 1,03 & 2,933 & 0,056 & \\
\hline 14 & 3,67 & 0,94 & 3,76 & 0,82 & 3,62 & 0,89 & 0,379 & 0,686 & \\
\hline 15 & 3,74 & 1,06 & 3,75 & 0,83 & 4,24 & 0,54 & $4,896^{*}$ & $0,009^{*}$ & $\mathrm{a}-\mathrm{c}, \mathrm{b}-\mathrm{c}$ \\
\hline 16 & 3,54 & 1,54 & 3,48 & 0,99 & 4,21 & 0,53 & $6,540^{*}$ & $0,002^{*}$ & $a-c, b-c$ \\
\hline 17 & 4,10 & 1,18 & 3,56 & 1,06 & 3,89 & 0,87 & $3,303^{*}$ & $0,040^{*}$ & $a-b, b-c$ \\
\hline
\end{tabular}

(1.Madde Tv., video, film izleme, 2. Müzik dinleme, indirme, 3. Oyun oynama, 4. Haberleşme (e posta), 5.Sohbet etme, 6. Futbol programların ve yorumları takip etme, 7. Gazete, dergi okuma, 8 . Ders, ödev için bilgiye ulaşma, 9. Yarışmalara katılma, 10. Bahis, iddia oyunları oynama- takip etme, 11. Spor aktivitelerini takip etme, 12. Alış veriş yapma, 13. Bankacılık işlemleri, 14. Haberleri takip etme, 15. Kendim ve takımımla ilgili haberleri takip etme, 16. Rakip takımların haberlerini takip etme, 17. Mesleki araştırma.) 
Tablo 15'e bakıldığında, birinci madde olan "TV, video, film izleme" görüşüne araştırma grubunun yaş değişkenine göre yapılan varyans analizi neticesinde anlamlı farklılık olduğu belirlenmiştir . İnterneti “TV, video, film izleme" amacıyla kullanma görüşünü 21-30 yaşındaki futbolcular 1-20 yaş ve 31 yıl ve üzeri yaşındaki futbolculara göre daha çok kullandıklarını yapılan anova test sonucunda belirlenmiştir. Buna göre, futbolcuların yaşı arttıkça internette TV, video, film izleme amac ile daha çok kullandığını söyleyebiliriz.

Yine Tablo 15'e bakıldığında, beşinci madde olan "sohbet etme" görüşüne katılımcıların yaş değişkenine göre yapılan varyans analizi neticesinde istatiksel olarak anlamlı farklılık olduğu belirlenmiştir . İnterneti "sohbet etme" amacı ile kullanma görüşüne 1-20 yaş aralığındaki futbolcular 21-30 yaş aralığındaki futbolcular ve 31 yıl ve üzerindeki futbolcular yaşındaki futbolculara göre daha çok kullandıklarını yapılan anova test neticesinde belirlenmiştir. Bu sonuçlar, futbolcuların yaşı arttıkça interneti sohbet etmek amacı ile daha az kullandığını söyleyebiliriz.

Tablo 15 değerlendirildiğinde, altıncı madde olan "futbol programlarını ve yorumları takip etme" görüşüne maddesine araştırma grubunun yaş değişkenine göre yapılan varyans analizi sonucunda anlamlı farklılığın olduğu görülmektedir . İnterneti "futbol programlarını ve yorumları takip etme" amacıyla kullanma görüşünü 21-30 yaş ve 1-21 yaşındaki futbolcular 31 yıl ve üzeri yaşındaki futbolculara göre daha çok kullandığı yapılan anova test neticesinde görülmüştür. Bu sonuçlar, futbolcuların yaşı arttıkça interneti futbol programları ve yorumlarını takip etmek amacı ile daha az kullandığını söyleyebiliriz.

Tablo 15' bakıldığında, yedinci madde olan "gazete, dergi okuma" görüşüne araştırma grubunun yaş değişkenine göre yapılan varyans analizi neticesinde istatiksel olarak bir farklılık olduğu belirlenmiştir. .İnterneti "gazete, dergi okuma" amacıyla kullanma görüşünü 21-30 yaş ve 1-21 yaşındaki futbolcular 31 yıl ve üzeri yaşındaki futbolculara göre daha fazla kullandıklarını uygulanan anova testi neticesinde görülmüştür. Bu sonuçlar, futbolcuların yaş düzeyi arttıkça gazete, dergi okuma amacı ile interneti daha az kullandığını söyleyebiliriz.

Yine Tablo 15 değerlendirildiğinde, onuncu madde olan "Bahis, iddia oyunları oynama-takip etme" görüşüne araştırma grubunun yaş değişkenine 
göre uygulanan varyans analizi neticesinde istatiksel olarak bir farklılık belirlenmiştir . İnterneti "bahis, iddia oyunları oynama-takip etme" amacı ile kullanma görüşüne 1-20 yaş aralığındaki futbolcular 21-30 yaş aralığındaki futbolcular ve 31 yıl ve üzerindeki yaşındaki futbolculara kıyasla daha fazla kullandığını uygulanan anova test neticesinde belirlenmiştir. Bu sonuçlar, futbolcuların yaş düzeyi arttıkça interneti bahis, iddia oyunları oynama-takip etme amacı ile daha az kullandığını söyleyebiliriz.

Tablo 15 değerlendirildiğinde, on birinci madde olan "spor aktivitelerini takip etme" görüşüne araştırma grubunun yaş değişkenine göre uygulanan varyans analizi neticesinde istatiksel olarak bir farklılık bulunduğu belirlenmiştir . İnterneti "spor aktivitelerini takip etme" amaci ile kullanma görüşüne 1-20 yaş aralığındaki futbolcular ve 21-30 yaş aralığındaki futbolcular 31 yıl ve üzerindeki futbolculara kıyasla daha fazla kullandığı uygulanan anova test neticesinde görülmüştür. Bu sonuçlar, futbolcuların yaş seviyesi arttıkça interneti spor aktivitelerini takip etmek için daha fazla kullandığını söyleyebiliriz.

Tablo 15 incelendiğinde, on beşinci madde olan "kendim ve takımımla ilgili haberleri takip etme" görüşüne araştırma grubunun yaş değişkenine göre uygulanan varyans analizi neticesinde istatiksel olarak anlamlı bir farklılık belirlenmiştir . İnterneti "kendim ve takımımla ilgili haberleri takip etmek" için kullandığı görüşüne 1-20 yaş aralığındaki futbolcular ve 21-30 yaş aralığındaki futbolcular 31 yıl ve üzerindeki futbolculara göre daha az kullandığı uygulanan anova test neticesinde görülmüştür. Bu sonuçlar, futbolcuların yaş düzeyi arttıkça interneti kendim ve takımımla ilgili haberleri takip etmek için daha fazla kullandıklarını söyleyebiliriz.

Tablo 15 değerlendirildiğinde, on altınc madde olan "rakip takımların haberlerini takip etme" görüşüne araştırma grubunun yaş değişkenine göre uygulanan varyans analizi neticesinde istatiksel olarak bir farklılık olduğu belirlenmiştir . İnterneti "rakip takımların haberlerini takip etmek" için kullanma görüşüne 1-20 yaş aralığındaki futbolcular ve 21-30 yaş aralığındaki futbolcular , 31 yıl ve üzerindeki futbolculara kıyasla daha az kullandıklarını uygulanan anova test neticesinde belirlenmiştir. Bu sonuçlar, futbolcuların yaş düzeyi arttıkça interneti rakip takımların haberlerini takip etmek için daha fazla kullandıklarını söyleyebiliriz. 
Tablo 15 değerlendirildiğinde, on yedinci madde olan "mesleki araştırma" görüşüne araştırma grubunun yaş değişkenine göre uygulanan varyans analizi neticesinde istatiksel olarak bir farklılık olduğu belirlenmiştir . İnterneti "mesleki araştırma yapmak" için kullanma görüşüne 21-30 yaş aralığındaki futbolcular 1-20 yaş aralığındaki futbolcular ve 31 yıl ve üzerindeki futbolculara kıyasla daha az kullandıklarını uygulanan anova test neticesinde belirlenmiştir.

Araştırmaya Katılan Profesyonel Futbolcularm Yaş Değişkenine Göre Sportif Siteleri Takip Etme Durumuna İlişkin Görüşleri

Tablo 16. Araştırmaya Katılan Profesyonel Futbolcuların Yaş Değişkenine Göre Sportif Siteleri Takip Etme Durumuna İlişkin Görüşleri

\begin{tabular}{|c|c|c|c|c|c|c|c|c|c|}
\hline \multirow[t]{2}{*}{$\begin{array}{l}\text { M. } \\
\text { No }\end{array}$} & \multicolumn{2}{|c|}{$\begin{array}{l}\text { 1-20 yaş (a) } \\
(\mathrm{n}=67)\end{array}$} & \multicolumn{2}{|c|}{$\begin{array}{l}21-30 \text { yaş (b) } \\
(n=77)\end{array}$} & \multicolumn{2}{|c|}{$\begin{array}{l}31 \text { yaş ve üzeri } \\
\text { (c) } \\
(n=18)\end{array}$} & \multicolumn{2}{|c|}{ Varyans } & \multirow{2}{*}{$\begin{array}{l}\text { Fark } \\
\text { Olan } \\
\text { Gruplar }\end{array}$} \\
\hline & $\bar{X}$ & $\mathrm{~S}$ & $\bar{X}$ & $S$ & $\bar{X}$ & $\mathrm{~S}$ & $\mathbf{F}$ & p & \\
\hline 1 & 4,38 & 0,76 & 4,05 & 0,77 & 4,02 & 0,72 & 2,480 & 0,087 & \\
\hline 2 & 3,93 & 1,43 & 3,77 & 0,80 & 3,43 & 1,28 & 2,058 & 0,131 & \\
\hline 3 & 4,29 & 0,82 & 3,44 & 0,84 & 2,70 & 1,50 & $19,658^{*}$ & $0,000^{*}$ & $a-b, a-c$ \\
\hline 4 & 4,38 & 0,76 & 3,83 & 0,82 & 3,67 & 1,45 & $4,766^{*}$ & $0,010^{*}$ & $a-b, a-c$ \\
\hline 5 & 1,64 & 1,11 & 2,12 & 1,40 & 1,94 & 1,52 & 1,345 & 0,264 & \\
\hline
\end{tabular}

(1.madde Uluslararası maçlar takip etme 2.madde maçları canl takip etme 3.madde federasyon siteleri 4.madde Spor basının takip 5.madde Bahis siteleri.)

Tablo 16 değerlendirildiğinde, üçüncü madde olan "federasyon siteleri" görüşüne araştırma grubunun yaş değişkenine göre uygulanan varyans analizleri neticesinde istatiksel olarak bir farklılık belirlenmiştir . İnterneti "federasyon siteleri" görüşüne 1-20 yaş aralığındaki futbolcular 21-30 yaş aral1ğındaki futbolcular ve 31 yıl ve üzerindeki futbolculara kıyasla daha fazla benimsedikleri uygulanan anova test neticesinde görülmüştür. Bu sonuçlar futbolcuların yaş seviyesi yükseldikçe federasyon sitelerini daha az takip ettiklerini söyleyebiliriz.

Tablo 16 değerlendirildiğinde, dördüncü madde olan "spor basını takip" görüşüne araştırma grubunun yaş değişkenine göre uygulanan varyans analizleri neticesinde istatiksel olarak bir farklılık belirlenmiştir . İnterneti "spor basını takip etmek" görüşüne 1-20 yaş aralığındaki futbolcular 21-30 yaş aralığındaki futbolcular ve 31 yıl ve üzerindeki futbolculara göre daha fazla 
benimsediklerini uygulanan scheffe testi neticesinde belirlenmiştir Bu sonuçlar, futbolcuların yaş seviyesi yükseldikçe spor basınını daha az takip ettiklerini söyleyebiliriz.

\section{Profesyonel Futbolcularn Yaş Değisşkenine Göre Bilgisayar ve Playstation Oyunlarna Katılma Durumlarına İlişkin Görüşleri}

Tablo 17. Profesyonel Futbolcularnn Yaş Değişkenine Göre Bilgisayar ve Playstation Oyunlarnna Katılma Durumlarnna İlişkin Görüşleri

\begin{tabular}{|c|c|c|c|c|c|c|c|c|c|}
\hline \multirow[t]{2}{*}{$\begin{array}{l}\text { M. } \\
\text { No }\end{array}$} & \multicolumn{2}{|c|}{$\begin{array}{l}1-20 \text { yaş }(a) \\
(n=67)\end{array}$} & \multicolumn{2}{|c|}{$\begin{array}{l}21-30 \text { yaş }(\mathbf{b}) \\
(n=77)\end{array}$} & \multicolumn{2}{|c|}{$\begin{array}{l}31 \text { yaş ve üzeri } \\
\text { (c) }(n=18)\end{array}$} & \multicolumn{2}{|c|}{ Varyans } & \multirow[t]{2}{*}{$\begin{array}{l}\text { Fark Olan } \\
\text { Gruplar }\end{array}$} \\
\hline & $\bar{X}$ & $S$ & $\bar{X}$ & $S$ & $\bar{X}$ & $S$ & F & $\mathrm{p}$ & \\
\hline 1 & 4,00 & 1,29 & 2,44 & 1,49 & 3,56 & 1,31 & $16,914^{*}$ & $0,000^{*}$ & $a-b, b-c$ \\
\hline 2 & 3,96 & 1,30 & 2,51 & 1,42 & 2,92 & 1,01 & $13,710^{*}$ & $0,000^{*}$ & $a-b, a-c$ \\
\hline 3 & 4,32 & 0,94 & 2,44 & 1,37 & 2,50 & 1,20 & $26,580^{*}$ & $0,000^{*}$ & $a-b, a-c$ \\
\hline 4 & 3,00 & 1,63 & 2,41 & 1,42 & 1,96 & 1,37 & $3,753^{*}$ & $0,026^{*}$ & $a-b, a-c$ \\
\hline 5 & 4,41 & 0,71 & 3,03 & 1,77 & 4,39 & 1,16 & $14,564^{*}$ & $0,000^{*}$ & $a-b, b-c$ \\
\hline 6 & 3,16 & 1,86 & 2,45 & 1,59 & 2,14 & 1,20 & 3,367 & $0,037^{*}$ & $a-b, a-c$ \\
\hline
\end{tabular}

(1.Madde Bilgisayar da futbol oynama futbol becerimi geliştiriyor, 2. Madde Bilgisayarda futbol oynama futbol oyun stratejimi geliştiriyor 3.Madde Futbol oyununda kullandığım taktiksel varyasyonları antrenman ve maçlar da kullanırım 4.Madde Bilgisayar oyunlarnı kaybettiğim zaman üzülüyorum 5.Madde Bilgisayar oyunlarnı kazanmak veya kaybetmek beni duygusal olarak etkilemiyor 6.Madde Bilgisayardaki futbol oyunlarna gerçek maç gibi konsantre olurum)

Tablo 17 değerlendirildiğinde, birinci madde olan "bilgisayarda futbol oynama futbol becerimi geliştiriyor" görüş maddesine araştırmaya katılanların yaş değişkenine göre yapılan varyans analizi sonucunda anlamlı farklılı̆ı̆n olduğu görülmektedir . "Bilgisayarda futbol oynama futbol becerimi geliştiriyor" görüşünü 21-30 yaş aralığındaki futbolcular 1-20 yaş aralığındaki futbolcular ve 31 yıl ve üzerindeki futbolculara göre daha az benimsedikleri yapılan anova testi sonucunda görülmektedir.

Tablo 17 incelendiğinde, ikinci madde olan "bilgisayarda futbol oynama futbol oyun stratejimi geliştiriyor" görüşüne araştırma grubunun yaş değişkenine göre uygulanan varyans analizleri sonuçlarında istatiksel olarak bir farklılık belirlenmiştir . "Bilgisayarda futbol oynama futbol becerimi geliştiriyor" görüşüne 1-20 yaş aralığındaki futbolcular 21-30 yaşındaki futbolcular 
ve 31 yll ve üzerindeki futbolculara kıyasla daha çok benimsedikleri uygulanan anova test sonuçlarında belirlenmiştir. Bu sonuçlar, futbolcuların yaş seviyesi yükseldikçe arttıkça bilgisayarda futbol oynama futbol oyun stratejimi geliştiriyor görüşünü daha az benimsedikleri söylenebilir.

Tablo 17 incelendiğinde, üçüncü madde olan "futbol oyununda kullandığım taktiksel varyasyonları antrenman ve maçlarda kullanırım" görüşüne araştırma grubunun yaş değişkenine göre uygulanan varyans analizleri neticesinde istatiksel olarak bir farklılık belirlenmiştir . "futbol oyununda kullandığım taktiksel varyasyonları antrenman ve maçlarda kullanırım" görüşüne 1-20 yaş aralığındaki futbolcular 21-30 yaşındaki futbolcular ve 31 yıl ve üzerindeki futbolculara kıyasla daha çok benimsedikleri uygulanan anova testi neticesinde belirlenmiştir. Bu sonuçlar, futbolcuların yaş seviyesi yükseldikçe futbol oyununda kullandığım taktiksel varyasyonları antrenman ve maçlarda kullanırım görüşünü daha az benimsedikleri söylenebilir.

Tablo 17 incelendiğinde, dördüncü madde olan "bilgisayar oyunların kaybettiğim zaman üzülüyorum" görüşüne araştırma grubunun yaş değişkenine göre uygulanan varyans analizleri neticesinde istatiksel olarak bir farklılık belirlenmiştir . "bilgisayar oyunlarını kaybettiğim zaman üzülüyorum" görüşüne 1-20 yaş aralığındaki futbolcular 21-30 yaş aralığındaki futbolcular ve 31 yıl ve üzerindeki futbolculara kıyasla daha çok benimsedikleri uygulanan anova testi sonucunda belirlenmiştir. Bu sonuçlar, futbolcuların yaş seviyesi yükseldikçe bilgisayar oyunlarını kaybettiğim zaman üzülüyorum görüşünü daha az benimsedikleri söylenebilir.

Tablo 17 incelendiğinde, beşinci madde olan “bilgisayar oyunlarını kazanmak veya kaybetmek beni duygusal olarak etkilemiyor" görüşüne araştırma grubunun yaş değişkenine göre uygulanan varyans analizleri sonucunda anlamlı farklılığın olduğu görülmektedir . "bilgisayar oyunlarını kazanmak veya kaybetmek beni duygusal olarak etkilemiyor" görüşünü 21-30 yaş aralığındaki futbolcular 1-20 yaş aralığındaki futbolcular ve 31 yıl ve üzerindeki futbolculara kiyasla daha az benimsedikleri uygulanan anova testi sonucunda belirlenmiştir.

Tablo 17 değerlendirildiğinde, altıncı madde olan "bilgisayardaki futbol oyunlarına gerçek maç gibi konsantre olurum" görüşüne araştırma grubunun yaş değişkenine göre uygulanan varyans analizleri neticesinde istatiksel olarak bir farklılık belirlenmiştir . "bilgisayardaki futbol oyunlarına gerçek maç gibi konsantre olurum" görüşüne 1-20 yaş aralığındaki futbolcular 21- 
30 yaş aralığındaki futbolcular ve 31 yıl ve üzerindeki futbolculara kıyasla daha çok benimsedikleri uygulanan anova testi sonucunda belirlenmiştir. Bu sonuçlar, futbolcuların yaş seviyesi yükseldikçe bilgisayar oyunlarını kaybettiğim zaman üzülüyorum görüşünü daha az benimsedikleri söylenebilir.

\section{Sonuçlar ve Öneriler}

$\mathrm{Bu}$ araştırmada profesyonel futbolcuların bilgisayar ve internet kullanımı hakkındaki görüşleri incelenmiştir.

Araştırmaya katılanların demografik özelliklerine bakıldığında yaş aralığı \%55.8'i nin 21-25 yaşları arasında olduğu belirlenmiştir. Araştırmaya katılanların medeni durumlarına bakıldığında \%70.8 bekar, eğitim durumları ise \%57.1 lise mezunu, \%40.9 da üniversite mezunu yada öğrencisi oldukları belirlenmiştir. Araştırma grubunun demografik özellikleri incelendiğinde katılımcların genellikle, yaşlarının genç, lise ya da üniversite mezunu oldukları veya okullarına devam ettikleri ve medeni durum açısından bekar kişilerden oluşmaktadır. Tel (2011) halı sahalarda futbol oynayan bireylerin bazı değişkenler açısından incelediği araştırma sonuçlarıyla benzerlik gösterdiği görülmektedir Abakay ve Kuru (2010) yaptıkları çalışmada amatör futbolcuların 18-33 yaş aralığında değiştiğini tespit etmişlerdir. Araştırmaya katılan profesyonel futbolcuların $\% 43.9$ u süper ligde, $\% 52$ de 3 . Ligde futbol oynadıkları belirlenmiştir. Profesyonel futbolcuların \%31.1 bir saat, \%28.5 ise 2 saat internet ve bilgisayar başında zaman geçirdikleri belirlenmiştir. 3 saat ve üzeri internet ve bilgisayar başında zaman geçirenlerin oranı \% 40.1 olarak görülmektedir. İnternet ve bilgisayar başında zaman geçirme oranlarının yüksek olduğu görülmüş̧ür. Tel ve Erdoğan (2015) yaptıkları araştırmada doktorların internet kullanım düzeylerinin yüksek olduğu belirlemiştirler. Bu sonuçlar gelişen teknolojiyle beraber akıllı telefonlarda meydana gelen değişimler neticesinde internete bağlanmak kolay ve ucuz olduğundan internete bağlı zaman geçirme sürelerinin yükseldiği kanısındayız.

Araştırmada yer alan profesyonel futbolcuların \%84,3'ünün kendilerine ait bilgisayarlarının olduğu görülmektedir. Tel (2015) yaptığı çalışmada ortaokul öğrencilerinin bilgisayara sahip olma oranının \%57.8 olduğunu tespit etmiştir. Son zamanlar özellikle internete kolaylıkla bağlanabilen akıllı telefonların yaygınlaşmasıyla beraber bu oranların yükseldiği düşünülmektedir. İnsanların evlerinde kendilerine ait bilgisayarlarının bulunması bilgisayar 
oyunların oynamasında önemli bir etken olup olumsuz yönde etkilemektedir (Koçak ve Köse, 2014).

Araştırmada yer alan profesyonel futbolcuların \% 56,2'nin playstation oyunlarını oynadığını, \% 34,0'nün bazen oynadığını, \% 9,8'nin ise playstation oyunlarını oynamadığını tespit edilmiştir. Tel ve ark. (2017) tarafından amatör futbolculara yönelik yapılan araştırmada katılımcıların $\%$ 55,0'inin playstation oyunların oynadığını, \% 29,0'unun bazen oynadığını, \% 16,0'sının ise playstation oyunlarını oynamadıklarını belirlemiştirler. Araştırmada katılımcıların playstation oyunlarını oynama oranını $\% 84$ gibi çok yüksel bir orana sahip olduğu görülmektedir. Futbolun çoğunlukla gençler arasında sıklıkla oynandığı bilinmektedir. Uluyol ve ark., (2014) yaptıkları çalışmada üniversite öğrencilerinde \%92,5'lik gibi büyük bir çoğunluğunun bilgisayar oyunlarını oynadıklarını tespit etmişlerdir.

Araştırmaya katılan profesyonel futbolcuların \% 76,1'i 1 saat, \% 47,9'u evde playstation oyunları oynadığı belirlenmiştir. Tel ve Ark. (2017) tarafından amatör futbolculara yönelik yapılan araştırmada katılımcıların \% 54,2'sinin 1 saatten daha az oyun oynadığı, iki saat oyun oynayanların oranın ise \%20.9 olduğunu belirlemiştirler. 3 saat ve üzerinde oyun oynayanların oranı ise \%12.4 olarak tespit edilmiştir. Bilgisayar ile video oyunlarının ergen bireylerde bağımlılık yaptı̆̆ı yapılan çalışmada görülmektedir (Koçak ve Köse, 2014).

Araştırmaya katılan profesyonel futbolcuların \% 52,8'inin futbol oyununu oynadığı, \% 40,9'unun eğlenmek amaciyla ve \% 49,5'inin PES adlı oyunu oynadığı belirlenmiştir. Tel ve Ark. (2017) tarafından amatör futbolculara yönelik yapılan araştırmaya katılanların, \% 43,8' inin futbol oyununu oynadığı belirlenmiştir. Yapılan araştırmalarda üniversite öğrencilerinin playstation oyunları içerisinde en fazla oynadığı strateji ve yarış olduğu belirlenmiştir (Uluyol ve Ark. 2014). Amatör olarak futbol oynayan bireylerin futbol sporunu sevdiğinden dolayı futbol oyununu daha fazla oynadığı söylenebilir. Profesyonel sporcular amatör futbolculara göre playstation oyunlarını daha fazla oranlarda oynamaktadirlar.

Araştırmaya katılan profesyonel futbolcuların niçin playstation oynadıkları sorusuna verdikleri cevaplarda 40,9'u eğlenmek, \%32,7' si stres atmak, $\% 16,2$ ' de boş zamanları değerlendirmek olarak belirtmişlerdir. Tel ve Ark (2017) tarafından yapılan araştırmada katılımcıların \% 40,2'si eğlenme amaçlı 
ve $\% 29,6^{\prime}$ lik kısmı stres atmak için $\% 19,7$ si ise boş zamanlarını değerlendirmek için bu tür oyunları oynadıklarını ifade ermişlerdir.

Uluyol ve ark. (2014) yaptıkları araştırmada katılımcların; \%64.51'nin eğlence amaçlı, \%19.35 stres atmak için, \%12.90'unun ise boş zamanlarını değerlendirmek için oyun oynadıklarını ifade etmişlerdir. Ayrıca Uluyol ve ark., (2014) yaptığı araştırmada üniversite öğrencilerinin büyük bir çoğunluğunun eğlenmek ve stres atmak için oyun oynadıklarını belirtmişlerdir. Günümüzde bilgisayarda oynanan oyunlar ergen bireyler için eğlenmek ve boş zamanlarını değerlendirme aracı olarak görülmektedir. (Koçak \& Köse, 2014). Tüzün ve Özdinç (2010) yaptıkları çalışmada üniversite öğrencilerinin yaklaşık \%40'ının bilgisayar oyunlarını eğlenmek için oynadıklarını ve bu sonuçlar çalışmamızla benzerlik gösterdiği görülmektedir.

Araştırmaya katılan profesyonel futbolcuların iletişime sahip olma durumlarına bakıldığında e posta \%83.8, facebook \%82.5 ve MSN kullananların oran $\% 70.8$ olduğu belirlenmiştir. Futbolcuların sosyal medyayı çok iyi kullandıkları görülmektedir. Tel ve Ark (2017) tarafından amatör futbolculara yapılan araştırmada Araştırmaya katılanların \% 95,8'inin Facebook hesabının olduğu ve \% 28,8'inin günde birkaç kez Facebook hesaplarını takip ettiği belirlenmiştir. Ülkemizde özellikle gençler tarafından facebook kullanıldığı belirlenmiştir. Tel ve ark., (2017) yaptıkları çalışmada futbolcuların sosyal medya platformları arasında en çok facebook kullandıkları (We are Social, 2017) ve araştırmaya katılanların e posta adresi bulunanların oranı $\% 88.5$ olarak belirlemişlerdir. Bu oranın yüksek olması araştırmaya katılan grubun genç yaşlarda olması ile açıklanabilir.

Profesyonel futbolcuların oynadıkları futbol oyun türlerine bakıldığında \% 34,1'inin FIFA, \% 57,0'1nın PES, \% 13,0'1nın Football Manager ve \% 2,0'ının da diğer futbol oyunlarını oynadıkları görülmektedir. Tel ve Ark (2017) tarafından amatör futbolculara yapılan araştırmaya katılan futbolcuların oynadıkları futbol oyununa bakıldığında \% 57,0'ının PES adlı oyunu oynadığı belirlenmiştir. Akın (2008) tarafından yapılan araştırmada katılanların \%76.6' sını PES oyununu favori olarak oynadıkları belirlenmiştir. Amatör ve profesyonel futbolcular tarafindan oynanan oyunlar benzerlik göstermektedir. 
Araştırmaya katılan profesyonel futbolcuların yaş değişkenine göre bilgisayar ve internet kullanımına ilişkin görüşlerine bakıldığında 1-20 yaş ve 2130 yaşındaki futbolcular, 31 yaş ve üstü futbolculara göre "gazete-dergi okuma", "kendim ve takımımla ilgili haberleri takip etme", "rakip takımların haberlerini takip etme" ve "spor aktivitelerini takip etme" amaciyla daha çok kullandıkları belirlenmiştir.

Araştırmaya katılan profesyonel futbolcuların yaş değişkenine göre sportif siteleri takip etme durumlarına ilişkin görüşlerine bakıldığında 1-20 yaşındaki futbolcuların 21-30 yaş ve 31 yaş ve üzeri futbolculara göre daha çok "federasyon siteleri" ve "spor basını" takip ettikleri belirlenmiştir.

Araştırmaya katılan profesyonel futbolcuların yaş değişkenine göre bilgisayar ve playstation oyunlarına katılma durumlarına ilişkin görüşlerine bakıldığında 1-20 yaşındaki futbolcuların 21-30 yaş ve 31 yaş ve üzeri futbolculara göre "bilgisayarda futbol oynama, futbol oyun stratejimi geliştiriyor", "futbol oyununda kullandığım taktiksel varyasyonları antrenman ve maçlarda kullanırım", "bilgisayar oyunların kaybettiğim zaman üzülüyorum" ve "bilgisayardaki futbol oyunlarına gerçek maç gibi konsantre olurum" görüş maddelerini daha çok benimsedikleri belirlenmiştir. Profesyonel futbolcuların sanal ortamda oynadıkları oyunu gerçek oyunmuş gördükleri ve burada geliştirdikleri taktikleri sahada uygulamaya çalıştıkları belirlenmiştir.

Sonuç olarak, profesyonel olarak futbol oynayan futbolcuların bilgisayar ve interneti sıklıkla kullandıklarını, iletişime açı olduklarını, playstation oyunlarını sıklıkla oynadıklarını, oyun türü en fazla futbol oyunlarını oynadıklarını tespit etmişlerdir. Ayrıca araştırmada yer alan Profesyonel futbolcuların playstation oyunlarını gerçek bir oyun gibi algılayarak oynadıklarını belirlenmiştir. 


\title{
EXTENDED ABSTRACT
}

\section{Perceptions Of Professional Football Players About Using Computer - Internet And Playstation Games}

\author{
Mikail Tel \\ Furat University
}

Football is a sports branch that is frequently practiced in professional and amateur levels as well as synthetic pitches and school teams in Turkey. In parallel to this popularity, football players are viewed and respectable individuals in society. Football and football players always take place on social media. This constantly increases the popularity of football and football players. Today, along with rapid development in the science and technology world, the usage of computers-internet increases. Football also takes place on social media frequently. Today, one-third of the news in the media is conducted on the subject of sports and football. Professional football and the lives of football players who practice this sport are shared on social media. Within this scope, the usage of computer-internet, having communication and frequency, and the period of playing digital games of professional football players are constantly wondered. This study aims to determine the perceptions of professional football players towards the computer, internet and PlayStation games.

The perceptions of professional football players towards the usage of computer, internet and PlayStation games were investigated according to different variables and answers for the following questions were searched:

1- Individual and socioeconomic levels of professional football players

2- Computer and internet usage levels and frequencies of professional football players

3- Determination of technology and social media usage levels of professional football players

This study was conducted to determine the perceptions of professional football players towards the computer, internet and PlayStation games. The study was conducted with the surveying model and had a descriptive 
quality. Surveying models are research approaches that aim to describe a past or present phenomenon (Karasar, 2010).

The population of the study covers the teams that competed in the 2015-2016 season in Turkey. The sample of the study consisted of 154 professional football players who played in these sports clubs and who agreed to participate in the study voluntarily. These sports clubs consisted of professional football players who played in "Elazığspor, Diyarbakırspor, Adıyamanspor, Malatyaspor and Denizlispor". In the determination of the sports clubs and players, the random sampling method was employed and the questionnaires were conducted with the principle of volunteerism. The study was conducted by the researcher who went to the football clubs.

In this study, the data were collected using the questionnaire method. In the development of the questionnaire form, expert opinions were received as well as conducting a literature review. In the questionnaire, a 5point Likert-type scale was used. The scale included responses as "Strongly Agree, Agree, Indecisive, Partially Agree, Strongly Disagree".

As a result of the factor analysis conducted for the participation status of professional football players in the computer, internet and PlayStation games, it was determined that the $\mathrm{KMO}$ and Bartlett test values were 0.684 and 550.184, respectively in addition to the Cronbach Alpha value of 0.758 .

In the data analysis, SPSS statistics package software was used. To determine the demographic information and the levels of computer and internet usage levels of athletes who participated in the study, the percentage $(\%)$ and frequency (f) analyses were conducted. According to the age variable of the participating athletes, one-way variance analysis (ANOVA) was used to determine their perceptions according to the athletes' status of using computer-internet and participating in computerPlayStation games.

When the demographic characteristics of the participants in the study were investigated, it was determined that $58 \%$ of the age distribution was between 21 and 25 years old. When the marital status variable of the participants was examined, it was determined that $70.8 \%$ of them were single in addition to $57.1 \%$ of the participants who had high school degrees and $40.9 \%$ of them were university graduates or students. When the demog- 
raphic characteristics of the study group were investigated, it was observed that the participants were generally young in terms of age, had high school or university degrees or continued studying in their schools as well as being single in terms of marital status. It was determined that the professional football players who participated in the study included $43.9 \%$ of players in the super league and $52 \%$ of the players who played in the third league. It was determined that $31.1 \%$ of the football players spent one hour and $28.5 \%$ of them spent two hours on the internet and computers. It was observed that $40.1 \%$ of the participants spent 3 hours and above for the internet and computers.

It was observed that $84.3 \%$ of the professional football players in the study had personal computers. It was determined that $56.2 \%$ of the professional football players in the study played PlayStation games in addition to $34.0 \%$ of the participants who played them sometimes and $9.8 \%$ of them who never played PlayStation games. It was also determined that $76.1 \%$ of the professional football players in the study played PlayStation games for 1 hour and $47.9 \%$ of them played them at home. It was determined that $52.8 \%$ of the professional football players in the study played football and $40.9 \%$ of them played them for fun in addition to $49.5 \%$ of them who played the game called PES. For the question of reasons for playing PlayStation games, it was determined that $32.7 \%$ of the football players played it to relieve stress and $16.2 \%$ of them played them for making use of leisure time. When the types of football games played by professional football players were investigated, it was observed that $34.1 \%$ of them played FIFA and $57.0 \%$ of them played PES in addition to $13.0 \%$ of them who played Football Manager and 2.0\% of them who played other football games.

According to the age variable of the professional football players in the study, when their perceptions towards using computers and the internet were investigated, it was determined that football players who were 1-20 years old and 21-30 years old used them for "reading newspaper-magazines", "following news about myself and my team", "following the news about rival teams" and "following sports activities" more compared to football players who were 31 years old and above. According to the age variable of the professional football players in the study, when their percep- 
tions towards following sportive websites were investigated, it was determined that the football players who were 1-20 years old followed the websites, "federation websites" and "sports press", more compared to football players who were 21-30 years old and 31 years old and above. According to the age variable of the professional football players in the study, when their perceptions towards participating in the computer and PlayStation games were investigated, it was determined that football players, who were 1-20 years old, adopted perception items such as "playing football in computers develop my football game strategies", "I use the tactical variations that I use in football games in training and matches", "I feel disappointed when I lose computers games" and "I concentrate for the football games in computers just as real matches" more compared to football players who were 21-30 years old and 31 years old and above. It was observed that professional football players viewed the virtual football games they play as real games and they attempted to practice the tactics they developed there in the field.

In conclusion, it was determined that football players, who play football professionally, used computers and the internet frequently while playing PlayStation games frequently in addition to playing football games the most in terms of the type of games. Additionally, it was determined that the professional football players in the study perceived and played the PlayStation games as real games.

\section{Kaynakça / References}

Abakay, U. ve Kuru, E. (2010). Profesyonel ve amatör futbolcuların statü değişkeni açısından başarı motivasyonu farklılıkları. Niğde University Journal of Physical Education And Sport Sciences, 4(3), 186-191.

Akbaş, D.M. (2002). İnternet iletişimi ve demokrasi üzerindeki etkileri. Yayınlanmamış Yüksek Lisans Tezi, KocaeliÜniversitesi, Sosyal Bilimler Enstitüsü, Kacaeli.

Akın, E. (2008). Elektronik spor: Türkiye'deki elektronik sporcular üzerine bir araştırma. Yüksek Lisans Tezi, Anadolu Üniversitesi Sağlık Bilimleri Enstitüsü, Beden Eğitimi ve Spor Anabilim Dalı, Eskişehir. 
Arnas, Y.A. (2005). Evaluation of using interactive communication tools habit of 3-18 age group children and adolescents. The TurkishOnline Journal Of Educational Technology - Tojet, 4(4), 59-66.

Bila, C. (2001). Bireysel ve kitle iletişim aracı olarak internet ve toplumsal etkileri. Yüksek Lisans Tezi, Gazi Üniversitesi, Ankara.

Binark, M., ve Bayraktutan, G. S. (2011). Dijital Oyun Kültürü Haritasında Oyuncular:Dijital Oyuncuların Habituslarıve Kariyer Türevleri. Aydemir A.T (Derleyen), İstanbul, Alternatif Bilişim.

Can, U.A. (1997). Internet kitabr. Ankara:Adanet.

Çelen, F.K., Çelik, A., ve Seferoğlu, S.S. (2011). Çocukların internet kullanımları ve onları bekleyen çevrim-içi riskler. Akademik Bilişim, 2, 1-8.

Games For Adults To Play Even. www.glreach.com/globstats/, 06.08.2004.

Göknur, B.E. (2000). İnternet'in sosyolojik boyutu. III. Ulusal Sosyoloji Kongresi, Eskişehir.

Güllü, M., Arslan, C., Dündar, A., ve Murathan, F. (2012). Examination of primary school children's computer, game addiction. Adryaman University Institute of Social Sciences Magazine Year, 5(9), 89-100.

Gündoğdu, C., Karataş, Ö. ve Nacar, E. (2011). Malatya' daki amatör futbolcuların futbola yönelmelerinde medyanın etkisi ile ilgili görüşleri. e-Journal of New World Sciences Academy, 6(1), 73-80.

Gürcan, A., Uslu, R., ve Özhan, S. (2008). Digital games and their effect on children. Research Report of T.R General Directorate of Family and Social Researches, November, Ankara.

İnternet Kullanıcısı 1 Milyara Ulaştı. www.ntvmsnbc.com/news/288144.asp. 2017.

İnternet Ve Sosyal Medya Kullanıcı İstatistikleri 2017. http://www.dijitalajanslar.com/internet-ve-sosyal-medya-kullanici-istatistikleri-2017/ 07.11.2017.

Karasar, N. (2010). Bilimsel araştırma yöntemi. Ankara:Nobel Yayınları.

Kıran, Ö. (2013). A study on the secondary school students' interest in the computer games containing violence. VII. Sociology Congress. Proceedings Book, 02.05, October, Muğla, 55-63.

Koçak, H., ve Köse, Z. (2014). Ergenlerin bilgisayar oyunu oynama alışkanlıkları ve sosyalleşme süreçleri üzerine bir araştırma:Kütahya İli örneği. Dumlupınar Üniversitesi Sosyal Bilimler Dergisi, Kütahya Özel Sayısı, 21-32.

Köksal, A.T., Oktay, D., ve Eser, S. (1999). Kim korkar bilgisayardan: İnternet. İstanbul:Pusula Yayınevi 
Korkusuz, M.E. ve Karamete, A. (2013). Educational game development models. Necatibey Eğitim Fak. Elektronik Fen ve Matematik Dergisi, 7(2), 78-109.

Önür, N., ve Kalaman, S. (2016). Dijital gündelik yaşam: Yeni toplumsallıklar ve dijital yabancilaşma. The Journal of Academic Social Science, 4(35), 269-289.

Spor Hizmetleri Genel Müdürlügüu. www.sgm.gsb.gov.tr. 1.11.2017.

Spor İstatistikleri. www.tuikspor istatistikleri 2007, 1.11.2017.

Tel, M. (2011). Halı Sahada Futbol Oynayanların Yaralanma Durumlarının Bazı Değişkenlere Göre İncelenmesi. Fırat Üniversitesi Sağlık Bilimleri Tıp Dergisi, 25 (3), 125 - 131.

Tel, M. (2015). Examination of students' digital gaming habits at secondary school level in Elazig Province of Turkey. Educational Research and Reviews, 10(8), 1300-1310.

Tel, M., ve Erdoğan, R. (2015). Doktorların boş zaman etkinliğine katılma durumlarınin incelenmesi. International Journal of Science Culture and Sport (IntJSCS), 4, 383-395.

Tüfekçi, A. (2007). Bilgisayar öğretmen adaylarının bilgisayar oyunu oynama alışkanlıkları. Gazi Üniversitesi Endüstriyel Sanatlar Eğitim Fakültesi Dergisi, 21, 38-54.

Türkiye'de İnternet Kullanım Alışkanlıkları.www.guvenliweb.org.tr/haber-detay/turkiyenin-internet-kullanim-aliskanliklari-tuik-2018, 15.09.2019 ind.

Tüzün, H., ve Özdinç, F. (2010). Öğretmen adaylarının bilgisayar oyunu oynama alışkanlıkları ve tercihlerine yönelik bir durum çalışması. Uluslararası Öğretmen Yetiştirme Politikaları ve Sorunları Sempozyumu II, 16-18 Mayıs Hacettepe Üniversitesi, Beytepe- Ankara.

Uluyol, Ç., Demiralay, R., Şahin, S., ve Eryılmaz, Ş. (2014). Öğretmen adaylarının oyun tercihleri ve bilgisayar oyunu oynama alışkanlıklarının incelenmesi: Gazi Üniversitesi Örneği. Journal Of İnstructional Technologies Teacher Education, 3(2), 1-7.

Ünsal, B., ve Ramazanoğlu, F. (2013). Spor medyasının toplum üzerindeki etkisi. Journal Of Research In Education And Teaching, 2(1) 36-46.

We Are Socials. www.wearesocial. 2017.

Wingateü, P. (2001). Internet. (Çev. S. İkiz), Ankara:Tübitak Yayınları,.

Yaman, M., ve Yaman, Ç. (2008). Beden eğitimi ve spor bölümü öğrencilerinin bilgisayar kullanma yeterlilikleri. Akademik İncelemeler, 3(1), 176-191. 


\section{Kaynakça Bilgisi / Citation Information}

Tel, M. (2020). Profesyonel futbolcuların bilgisayar - internet ve playstation oyunları kullanımına ilişkin görüşleri. OPUS-Uluslararası Toplum Araştırmaları Dergisi, 15(26), 4334-4361. DOI: 10.26466/opus.627504 